Original Research Paper

\title{
Morphology and Histochemistry of the Corpus Luteum (CL) of Ovaries of Pregnant and Infertile Cows
}

\author{
${ }^{1}$ Evgeny Skovorodin, ${ }^{1}$ Svetlana Bogolyuk, ${ }^{1}$ George Bazekin, ${ }^{1}$ Almaz Sharipov and ${ }^{2}$ Roman Khokhlov \\ ${ }^{I}$ Federal State Budgetary Educational Establishment of Higher Education "Bashkir State Agrarian University", \\ Ufa, Russian Federation \\ ${ }^{2}$ Federal State Budgetary Educational Institution of Higher Education "Penza State Agrarian University", \\ Penza, Russian Federation
}

\author{
Article history \\ Received: 20-07-2020 \\ Revised: 26-09-2020 \\ Accepted: 22-10-2020 \\ Corresponding Author: \\ Evgeny Skovorodin \\ Federal State Budgetary \\ Educational Establishment of \\ Higher Education "Bashkir \\ State Agrarian University", \\ 50th Anniversary of October \\ Street, 450001, Ufa, Russian \\ Federation \\ Email: skovorodinev@rambler.ru
}

\begin{abstract}
The purpose of our study is to study the functional morphology of the Corpus Luteum (CL) of the ovaries of pregnant and infertile cows in normal and pathological conditions. For that purpose, the ovaries of cows were examined after slaughter, histological and histochemical examination of the CL was carried out. For the antemortem examination of the ovary, the biopsy method developed by us was used. The effect of the synthetic analogy of prostaglandin F2 $\alpha$ - Klatiram was studied experimentally. It was established that the CL and luteal formations of the ovaries of those animals had significant changes in structure, which allowed us to develop morphological markers for diagnosing their morphofunctional state. It was found that the mass and size of the CL increases by two months, decreases by three months and then remain relatively stable. There is a growth of antral follicles that reach a size of more than $1 \mathrm{~cm}$ and then they undergo atresia of the obliteration type. The CL of the ovary cycle reaches its maximum development in the first ten or twelve days. Later, against the background of venous hyperemia and atrophic changes, it decreases, the lobulation of the parenchyma disappears and the vessels sclerose (the stage of involution). A method of biopsy of the bovine ovaries has been developed. The use of this method, with the experimental introduction of a synthetic analog of prostaglandin $\mathrm{F} 2 \mathrm{a}$, has proved that luteolytic processes in the CL of the ovary cycle develop due to violations of the microcirculatory bloodstream, development of necrobiotic processes in the parenchyma and stromal vascular dystrophy of the mesenchyma of the gland.
\end{abstract}

Keywords: Ovaries, Corpus Luteum, Morphology, Prostaglandin F2 $\alpha$

\section{Introduction}

The production of progesterone is believed to start after puberty, mainly by the ovarian Corpus Luteum (CL) and, in small amounts, by the adrenal glands, as well as by the placenta during pregnancy (Jameson and De Groot, 2015; Noakes et al., 2018; Rivera, 2016) although luteal atretic bodies are described in ensuing fetuses so far (Skovorodin et al., 2018).

For many years, the morphology and function of bovine ovarian lutein structures have been the subject of intense research and discussion (Costa et al., 2020; Mogheiseh et al., 2020; Walusimbi and Pate, 2014; Xavier et al., 2012). The cellular composition of the CL has not been definitively determined (Fields and Fields, 1996; Fields et al., 1992; Parkinson et al., 1994). The function of antral and cystic CL, as well as the features of vascularisation of this gland, are unclear (Jaśkowski, 2019; Siqueira et al., 2019). The functional value of luteocyte cytoplasmic granules have not been established (Jaśkowski, 2019; Vargas et al., 2015). The available papers describe differences in the CL of pregnancy, ovary cycle and endometritis (Mogheiseh et al., 2020; Sawyer, 1995).

Histologically, the bovine CL is formed by granulosa luteal cells of large size and small theka-luteal cells which are located in different zones (Cools et al., 2013a; Walusimbi and Pate, 2014; Xavier et al., 2012). Large luteal cells of cysts and cyclic CL have significant morphological differences. Some authors describe a special class of "medium-sized" luteal cells that have significant morphofunctional features (Vargas et al., 2015). 
Pathological forms of CL (luteal cysts, persistent CL in the setting of uterine pathology) are one of the causes of infertility in cows. It is also because CL synthesizes not only progesterone but at least two other polypeptide hormones - relaxin and oxytocin. The latter may be local regulators of ovarian function (Siqueira et al., 2019). Various prostaglandins play a leading role in the regulation of morphological changes in CL (Berisha et al., 2018). For example, after administration of prostaglandin F2 $\alpha$ genes associated with luteocyte apoptosis are activated (Jonczyk et al., 2019).

The purpose of our study is to study the functional morphology of the CL of the ovaries of pregnant and infertile cows in normal and pathological conditions.

\section{Materials and Methods}

\section{Characteristics of Animals}

The work was performed on the dairy farm of Bashkir state agrarian university, in the slaughterhouse of the meat processing plant, as well as in the laboratory of morphology, pathology, pharmacy and non-infectious diseases of Bashkir state agrarian university. 3-5 years old cows of the black-and-white breed were used for the research.

Feeding, management and use of cattle were studied on the farm. An obstetric and gynecological examination was performed to analyze the reproductive function of each cow in detail. Gynecological disorders were diagnosed based on vaginal, rectal and ultrasound examinations, selective biochemical and hormonal blood tests (total protein content, inorganic calcium, phosphorus, acid capacity, carotene and progesterone).

On that basis, the animals were divided into the following groups: The first - 27 pregnant cows, from one to nine months of pregnancy (three for each month of pregnancy); the second - 21 cycling cows. The days of the estrual cycle were divided into seven periods, three days each. The third group - 25 infertile cows with ovarian dysfunction (persistent CL on the background of subinvolution of the uterus and endometritis - 10, with hypofunction of the ovaries - 5, with luteal and follicular cysts of the ovarian glands - 10).

\section{Morphological Study}

After slaughter, the reproductive organs of cows were carefully studied. The ovaries were weighed and examined; the size and presence of follicles, CL, red (luteal) and white (follicular) atretic bodies were registered. The ovaries were cut transversely using a plate device proposed by us for the morphometric study of the ovaries of cows. These are two metal rods from the syringe. The blades for safety razors were fixed on them using washers, so it was possible to get organ segments of the same thickness. The size of CL was measured in them; the number of luteal atretic bodies and antral follicles was registered. Pieces of various parts of the ovaries were fixed in a $10 \%$ solution of neutral formalin, anhydrous alcohol fixatives, liquid nitrogen and in cooled $2.5 \%$ glutaraldehyde.

The histochemical activity of dehydrogenases was detected in cryostat sections: Succinate (SDH), Lactate (LDH), reduced Nicotinamide Adenine Dinucleotide phosphate $\left(\mathrm{NADH}_{2} \mathrm{DH}\right)$, reduced Nicotinamide Adenine Dinucleotide phosphate $\left(\mathrm{NADPH}_{2} \mathrm{DH}\right)$ alkaline and acid phosphatase by Burston in modification.

The effect of the synthetic analog of prostaglandin F2 $\alpha$ - Klatiram (RF Patent RU 2123336 C1) was studied experimentally. The active ingredient of the drug is a complex coordination compound of cloprostenol (0.10$0.20 \mathrm{mg})$ with glycyrrhizic acid (0.8-1.5 mg) and tyrosine $(0.10-0.15 \mathrm{mg})$. The original composition makes it possible to significantly reduce the concentration of expensive and toxic prostaglandin components (10 times compared to known drugs) and thereby eliminate undesirable side effects (convulsions, diarrhea, increased pressure) caused by the use of drugs containing up to $500 \mathrm{mcg}$ of active prostaglandin.

A morphological manifestation of the luteolytic activity of the synthetic analog of prostaglandin F2 $\alpha$ was performed on 24 cows. Experimental cows $(n=18)$ were once intramuscularly injected with Klatiram on the 8th12 th day of the ovary cycle, against the background of actively functioning CL. Doses: 250, 500 and $1000 \mathrm{mg}$. Doses were selected according to the amount of active prostaglandin - cloprostenol, according to the official instructions for the drug.

The ovarian biopsy was performed twice $48 \mathrm{~h}$ after administration of the drug ( 9 cows) and $96 \mathrm{~h}$ ( 9 cows). The control group cows $(n=6)$ were intramuscularly injected with saline solution and the CL biopsy was performed twice: After $48 \mathrm{~h}$ ( 3 cows) and $96 \mathrm{~h}$ ( 3 cows).

For the CL biopsy, we used "The method of CL biopsy in cattle" developed by us (RF Patent RU 2083165) in the following way. The cow was fixed. A puncture was performed in the area of the middle third of the line connecting the external tuber of the Ilium with the caudal dermal fold. The skin was slightly pierced with a pointed scalpel and the injection was administered with a needle with a mandrel perpendicular to the surface of the croup by the right hand. Then the needle was advanced until its end could be detected by finger without damaging the rectum wall. The ovary was grasped by the ligament with the left hand and it was pulled caudally to the vault of the pelvic cavity near the end of the needle. The needle was inserted deeper, the mandrel was extracted and the CL was pierced. In so doing, a small piece of tissue remains in the opening of the needle. After removing the needle, the contents were squeezed out with the mandrel into the retainer or onto a slide. Biopsies of 
the left ovary followed the same pattern, but the puncture was performed with the left hand and the ovary was fixed with the right hand through the rectum.

The data collected were stored in Microsoft Excel sheets. This program was used to calculate the arithmetic mean и standard deviation. For significant effects, the means were compared using a Student's ttest at 5\% significance. The t-test is any statistical hypothesis test in which the test statistic follows a Student's t-distribution under the null hypothesis.

\section{Results}

The novelty of the methodology of our work is that we studied the ovary as a whole comprehensively using modern macroscopic, histological and histochemical methods. So, it was possible to compare results related to different levels of the arrangement of the organ. We found that the ovaries contained not only large CL but also luteinized follicles and atretic bodies, as well as luteal cysts. The development of these structures is accompanied by a decrease in the growth of antral follicles not only under normal (heifers in the early postnatal period, the beginning of the ovary cycle after ovulation) but also in pathological conditions (persistent CL, ovarian hypofunction, luteal cysts).

The structure of CL, the morphology of which has been studied in sufficient detail, cannot be considered simplistically. After conducting a comprehensive study, we convinced ourselves that CL of pregnancy, CL of the ovary cycle, persistent $\mathrm{CL}$ and luteal cysts have significant differences in the structure and, therefore, in endocrine activity although they are arranged in the same way. These structures are characterized by pronounced morphological changes and rapid regression processes.

By two months of pregnancy, the CL weight increases significantly by 1.2 times and then decreases by one third and remains stable (Table 1 ).

The CL diameter increases significantly by 1.4 times by the age of two months and then significantly decreases remaining slightly less than $2 \mathrm{~cm}$ before calving (Table 2).

For the first six months, the ovaries of pregnant cows contain single antral follicles of more than $1 \mathrm{~cm}$ in diameter. The number of antral follicles up to $1 \mathrm{~cm}$ in size decreases by two months of pregnancy and then their number increases to the maximum by four months of pregnancy. Then it decreases to a 2-month level (Table 3).

The number of red atretic bodies in the ovarian glands practically does not change during pregnancy. The number of white atretic bodies increases by the 2 nd month of pregnancy. At the same time, the number of antral follicles decreases significantly (Fig. 1A). By the 3rd month of pregnancy, the number of white atretic bodies increases; by the 4th month, it significantly increases and, having decreased by five months, it remains constant (Fig. 1B).

In cows, during the normal ovary cycle, the ovarian glands lie close to the oviduct and the horns of the uterus being located in the pelvic cavity, or they slightly hang over the pubic edge of the pelvic bones. They are oval, weighing 20-25 g, volume 21-25 cubic cm, 5-9 cm long (Fig. 1C). The relative size of the ovaries changes during the cycle since a significant part of these organs is formed by temporary formations - antral follicles and CL.

Table 1: Weight of the ovaries of pregnant cows ( $\mathrm{g}$ )

\begin{tabular}{llllllllll}
\hline $\begin{array}{l}\text { Term of pregnancy } \\
\text { (Month) }\end{array}$ & \multicolumn{1}{c}{} & 2 & 3 & 4 & 5 & 6 & 7 & 8 & 9 \\
\hline Ovary with CL & $12.1 \pm 1.2$ & $14.6^{*} \pm 0.8$ & $10.6^{*} \pm 0.7$ & $9.3 \pm 0.6$ & $10.1 \pm 0.8$ & $9.5 \pm 0.5$ & $9.4 \pm 0.4$ & $9.3 \pm 0.5$ & $9.7 \pm 0.8$ \\
Ovary without CL & $5.9 \pm 0.4$ & $6.1 \pm 0.5$ & $6.2 \pm 0.6$ & $5.7 \pm 0.4$ & $6.3 \pm 0.5$ & $5.7 \pm 0.4$ & $5.3 \pm 0.5$ & $5.8 \pm 0.4$ & $5.7 \pm 0.6$ \\
\hline
\end{tabular}

* Significant difference compared to the previous group $(\mathrm{P}<5 \%)$

Table 2: Diameter of the CL of pregnancy (mm)

\begin{tabular}{|c|c|c|c|c|c|c|c|c|c|c|c|c|c|}
\hline \multicolumn{14}{|l|}{ Term of pregnancy } \\
\hline Diameter $(\mathrm{mm})$ & $20.4 \pm 2.1$ & $28.4 * \pm 3.1$ & $23.1 * \pm$ & & 21.4 & & 19. & \pm 1.7 & & $2 \pm 1.8$ & $19.4 \pm 1.3$ & $18.9 \pm 1.5$ & $19.2 \pm 1.7$ \\
\hline \multicolumn{14}{|c|}{ * Significant difference compared to the previous group $(\mathrm{P}<5 \%)$} \\
\hline \multicolumn{14}{|l|}{ Term of pregnancy } \\
\hline \multirow[t]{2}{*}{ Ovary with CL } & Up to $10 \mathrm{~mm}$ & $18.3 \pm 1.2$ & $8.2 \pm 0.4$ & & \pm 1.1 & 20. & 1.5 & 16.2 & & $12.3 \pm 0.7$ & $10.7 \pm 0.9$ & $8.1 \pm 0.5$ & $8.3 \pm 0.7$ \\
\hline & More $10 \mathrm{~mm}$ & 0 & $1.1 \pm 0.1$ & & & 0 & & $1.1 \pm$ & & 0 & 0 & 0 & 0 \\
\hline \multirow[t]{2}{*}{ Ovary without CL } & $\mathrm{Up}$ to $10 \mathrm{~mm}$ & $19.3 \pm 1.3$ & $10.4 \pm 0.5$ & & $* \pm 1.7$ & 21. & 1.2 & 19.4 & & $9.3 \pm 0.6$ & $10.2 \pm 0.8$ & $9.5 \pm 0.6$ & $9.3 \pm 0.7$ \\
\hline & More $10 \mathrm{~mm}$ & $1.0 \pm 0.2$ & $1.1 \pm 0.1$ & & & 0 & & $2.3 \pm$ & & $2.2 \pm 0.2$ & 0 & 0 & 0 \\
\hline
\end{tabular}

\footnotetext{
* Significant difference compared to the previous group $(\mathrm{P}<5 \%)$
} 

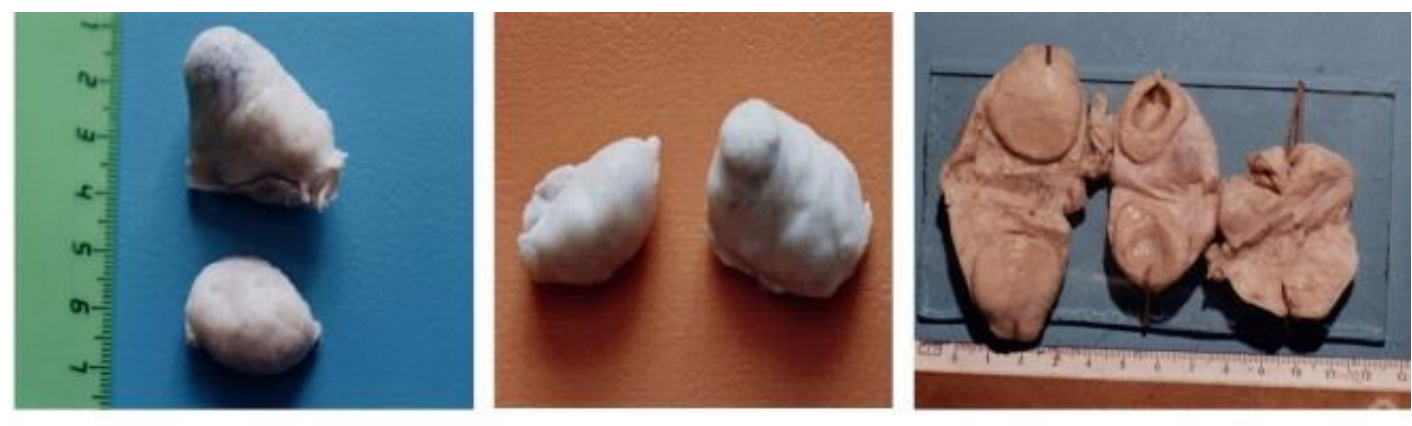

Fig. 1: CL of pregnant and infertile cows. (A). 2 months of pregnancy. A large CL is protruding above the surface of an organ with well-developed blood vessels. Both ovaries have antral follicles and atretic bodies. (B). 8 months of pregnancy. The CL of medium size without pronounced blood vessels on the surface, atretic bodies. In both ovaries, there are antral follicles. (C). Ovaries of cows in the incision. From left to right: CL in the middle of the ovary cycle; the CL of the ovary cycle with a cavity; persistent CL

The following macroscopic changes in the ovaries were found during the post-slaughter study of reproductive organs in the dynamics of the ovary cycle. In the first three days after ovulation, a ruptured follicle of about $2 \mathrm{~cm}$ is visible in the ovary. There was a loose red blood clot in its cavity. One or two well-visible follicles (up to $1 \mathrm{~cm}$ in diameter) with a thick wall and a jelly-like liquid in their cavity were found in another ovary. Besides, a small-sized CL is found in one ovary, in the state of involution. It does not protrude above the surface of the ovarian gland; its surface is whitish, without blood vessels. It is dark yellow in the incision, dry, with well-defined connective tissue partitions.

4-6 days after ovulation, the CL in one of the ovaries is large, light red or yellow, the apex is loose, mushroomshaped, slightly protruding above the surface of the ovary. The lobulation of the incision is not visible. There are 1-2 antral follicles with a diameter of $0.8-1.2 \mathrm{~cm}$.

8-9 days of the cycle: The CL is dense, its apex is nodulated and the luteal tissue in the incision is greyyellow, with pronounced lobulation. Large follicles with a diameter of up to one centimeter are not visible, but there are small and medium-sized follicles.

10-12 days: CL is developed as much as possible; the consistency is dense. The network of blood vessels on the surface is evident, but it does not reach the apex of the CL (Fig. 1C). The luteal tissue is bright yellow, lobular in the incision. In many cases, follicles with a diameter of about $1 \mathrm{~cm}$ are found.

Days 13-15 of the cycle: The surface of the CL with clearly visible blood vessels. Moreover, the vascular network reaches its apex. Due to the blood filling of blood vessels, the CL had a cyanotic tint of the surface and luteal tissue was bright yellow in the incision. A small cavity is revealed in the center; it is filled with a jelly-like liquid. It appears due to the development of atrophic processes as a result of the onset of CL involution. Large follicles with a diameter of about $1 \mathrm{~cm}$ are often found.
On the 16th-18th day, the CL slightly decreased in size and became dense; during enucleation by finger, it detached from the underlying tissue of the ovary quite easily. The vessels on the surface of the gland and at the base are filled with venous blood to overflowing; they are cyanotic. The vessels on the surface of the CL are not visible. In the incision, the CL is dense, bright yellow, dryish, with a weakly pronounced lobulation. A cavity filled with a yellow jelly-like liquid was sometimes found in the centre (Fig. 1C). In the ovaries - one or two follicles with a diameter of more than $1 \mathrm{~cm}$.

Day 19-21: The CL slightly protrudes or does not protrude at all above the surface; it is of whitish tint; blood vessels are evident. In the incision, the parenchyma of the CL is dark yellow and dry. There is one large, thin-walled fluctuating follicle in the paired ovary.

Thus, during the first ten days of the ovary cycle, the CL grows (Fig. 1C), its stroma, parenchyma and the vascular system are formed. On the 10th-12th day (Fig. 2A) of the ovary cycle, the CL reaches a peak. At a later stage, against the background of venous hyperemia and atrophic changes, it becomes smaller, lobulation of the parenchyma disappears and the walls of the vessels thicken.

According to our data, during pregnancy, the parenchyma of the CL develops from large luteal cells (Fig. 2A). Luteocytes have a granular cytoplasm with a diameter of $27.1 \pm 5.3$ microns and contain a large light core with a diameter of 10.1 microns. Quite often, there are hypertrophied cells of larger sizes. They contain either a large nucleus or even two nuclei. There are few neutral lipids in the cytoplasm of luteocytes. Phospholipids are distributed in the luteocytes of the CL of pregnancy relatively evenly; they are of dust-like or small-drop shape. Argyrophilic fibres reticulate in the CL. Large luteal cells are located in the mesh. Smaller theka-luteal cells are located along the course of argyrophilic fibres. They are $11.9 \pm 2.3$ microns in 
diameter, with the nucleus of $8.5 \pm 1.2$ microns. When staining by Van Gieson, no fuchsinophilous fibers are detected in the stroma of CL.

CL of the ovary cycle reaches its acme on the tenthtwelfth day of the ovary cycle. Thin interlayers with blood and lymphatic vessels go from its capsule to the centre. In the middle of the CL, there is a connecting "nucleus." In isolated cases, in that area, we found a cavity with the diameter of several millimeters to one centimeter, with a cloudy ropy liquid containing blood cells and desquamated epithelium. The cavity is lined with squamous epithelium and surrounded with fibrous connective tissue. This phenomenon should be taken into account during the ultrasound investigation.

The CL parenchyma of the ovary cycle is represented by large luteal cells with a diameter of $24.2 \pm 2.8$ microns and the nucleus with a diameter of $9.4 \pm 0.9$ microns. There are large luteocytes with vacuolated cytoplasm in which lipids are found. Large cells are more numerous in the CL of pregnancy, although the average difference is not reliable. There are small theka-luteal cells along the course of connective tissue trabeculae and around large luteal cells. Their diameter was $12.1 \pm 1.7$ microns, with the nucleus of $8.1 \pm 0.9$ microns. The shape of the cells is elongated or polygonal. Sometimes small theka-luteal cells surround granulose-luteal cells.

Small luteocytes predominate on the periphery of the $\mathrm{CL}$ and large ones are closer to the centre. As the $\mathrm{CL}$ is involuted, signs of protein-fat dystrophy and apoptosis are detected earlier in large luteal cells. Against this background, small luteocytes persist for a long time without visible changes. Fuchsinophilous collagen fibres appear in the stroma and the walls of blood vessels thicken.
Persistent CL against the background of subinvolution of the uterus had a large size (on average $20-25 \mathrm{~mm}$ in diameter). The apex protruded above the surface of the ovary for several millimeters in the form of a mushroom and had a depression in the centre. Against the background of chronic endometritis, persistent corpora lutea were smaller (on average 10-15 $\mathrm{mm}$ in diameter). More often, they protruded slightly above the surface of the ovary and were located inside the ovarian gland without a mushroom-like elevation (Fig. 1C).

Persistent CL against the background of uterine pathologies differed significantly from normal $\mathrm{CL}$ in their histological, histochemical and histoenzymatic properties. Luteocytes were characterized by atrophy and fatty degeneration of the cytoplasm. Stroma was characterized by an increase in fibrous changes and hyalinosis of the walls of blood vessels. Low activity of oxidation-reduction and hydrolytic enzymes, which was especially pronounced with the development of involution (Fig. 2B), was the morphogenetic mechanism for the development of these processes.

Based on the study of the structure of the corpora lutea, their hormonal activity (the concentration of progesterone in the blood serum), we distinguished two types of persistent CL: Hypofunctional and secreting progesterone actively. They had differences in the degree of luteal cell atrophy and stroma fibrosis (Fig. 2B and 2C). It was found that rectally diagnosed persistent ovarian corpora lutea in $44 \%$ of cows were nonfunctioning. However, these structures have a powerful endocrine and local effect on the ovarian glands, not only through the synthesis of progesterone but also via other local stimuli that inhibit the growth and ovulation of follicles.

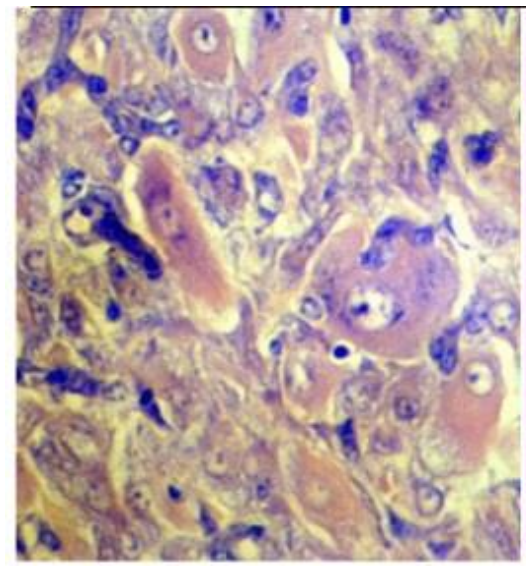

(A)

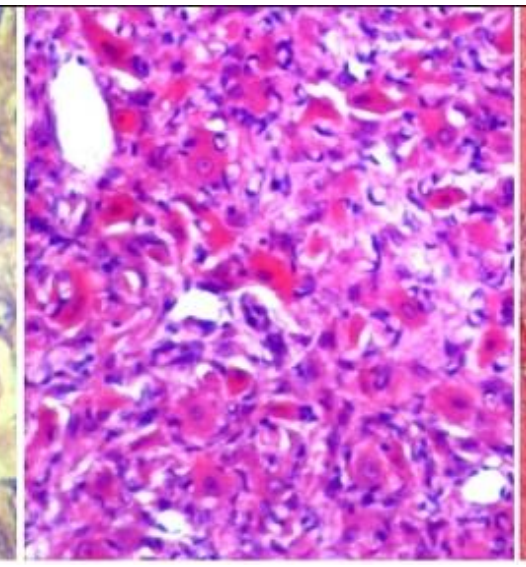

(B)

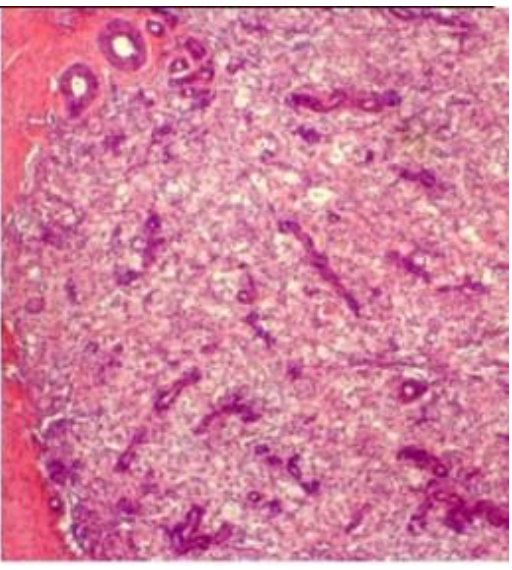

(C)

Fig. 2: CL. A. Peripheral zone of the CL of a pregnant cow. Large luteocytes with granular cytoplasm, theca-luteal cells. In the stroma, there are degranulated mast cells. Panoptic stain by Pappenheim. The image is enlarged 200 times. B. Hormoneactive persistent CL. Large luteocytes with dark eosinophilic cytoplasm. Pycnotic, elongated, vacuolated luteocytes. Pericellular edema, mucoid swelling. Hematoxylin and eosin. The image is enlarged 200 times. C. Persistent CL with low hormonal activity. Thick capsule, parenchymal atrophy and fibrous changes in blood vessels and stroma. Hematoxylin and eosin. The image is enlarged 100 times 
In ovarian hypofunction, atretic luteinized structures that resemble small involuting CL consist mainly of coarse fibrous collagenised connective tissue, with areas of hyalinosis. These formations contain single pycnotic luteal cells. Also, formations with a peculiar structure were found. Their centre is filled with a kind of connective tissue. Its collagen fibres spread from the protein shell radiating from the centre of the layers between which pycnotic luteal cells are located.

Luteal cysts are characterized not only by luteinization of some areas of the inner surface of the wall but also by a large amount of luteal tissue in the ovary. It is formed due to the luteinization of large tertiary follicles. Histologically, luteal tissue is characterized by the presence of large luteal cells with an average diameter of 21.2 \pm 2.4 microns. They are elongated in shape, with large rounded light nuclei. They are arranged as separate clusters. Small theka-luteal cells are few and they are concentrated mainly around blood vessels and along the course of trabeculae. Their cytoplasm is filled with brown pigment. Histoenzymological studies show that the activity of enzymes in these structures is high and approaches the same indicator in persistent CL.

A synthetic analog of prostaglandin F2 $\alpha$ has a pronounced luteolytic effect on the CL of cows with normal ovary cycles. Processes of involution of the CL manifested by the appearance of thick pycnotic nuclei of luteocytes are observed in the ovaries by the second day after drug administration at a dose of $250 \mathrm{mcg}$; a large amount of vacuoles of varied shape and volume is formed in their cytoplasm, which when stained with Sudan contain phospholipids and neutral fats. By the fourth day after administration of the drug, lysis of luteal cells increases and in $60-80 \%$ of animals involution of functioning $\mathrm{CL}$, luteinization and obliteration atresia of large and medium-sized follicles occur. At the same time, the growth and maturation of other follicles are activated, resulting in only individual animals coming in heat.

In cows, the drug at a dose of $500 \mathrm{mg}$ causes more intensive processes of CL involution, pycnosis and lysis of nuclei, vacuolation of the cytoplasm of luteal cells. In all animals, CL undergo lysis by the four days after the drug is administered.

In cows, this drug at a dose of $1000 \mathrm{mg}$ in two days after administration causes deep luteolytic processes. The sexual excitement stage is accompanied by luteinization, hemorrhagic and cystic atresia of large follicles. Ten days after the introduction of $1000 \mathrm{mg}$ of the drug, one nymphomaniac cow was forcedly taken to slaughter. Multiple cystic formations were found. Cysts were found in both ovaries. The organs simultaneously contained follicular thin-walled cysts, luteinized follicles and CL, suggesting ovulation. Most of the cysts were filled with clotted blood due to increased vascular porosity and ruptures. Hyperemia was also evident in other structures of the ovary, in the endometrium, the reticular zone of the adrenal cortex and the anterior pituitary lobe. Thus, high doses of the drug $(1000 \mathrm{mg})$, along with excessive activation of luteolytic processes in the CL, cause lysis of theka-luteal cells in the mature follicles, which leads to the formation of cysts. Therefore the drug in these doses cannot be recommended for causing the involution of the CL of the ovary cycle. The optimal dose of Klatiram for cows is $500 \mathrm{mg}$.

\section{Discussion}

Comparing the histology of the CL in three trimesters of pregnancy (Xavier et al., 2012), reported that the morphometric characteristics of luteal steroidogenic cells did not change. However, by the end of pregnancy, there was an increase in connective tissue, the number of fibroblasts and extracellular matter, especially after 190 days of pregnancy. Cell degeneration was observed in all trimesters of pregnancy but with greater intensity in the third trimester. There are following periods of evolution of CL during pregnancy: (1) up to 2 months of pregnancy the period of forming and acme; (2) up to 5 months - the period of primary senescence; (3) up to 8 months secondary morphofunctional acme; (4) up to calving - the period of secondary senescence (Sawyer, 1995).

Vargas et al. (2015) found that the volume of the cytoplasm and the nuclear volume of luteal cells significantly decreased between the first and second trimester of pregnancy. The volume ratio of the cytoplasm to the nucleus decreased during pregnancy. The amount of connective tissue and fibroblasts increased significantly throughout pregnancy. Histochemical studies of cytoplasmic granules indicate their protein nature. The number of luteal cells with granules increased throughout pregnancy, but the significant difference was observed between the first and second trimesters only.

According to our data, the mass and diameter of the CL of pregnancy increase by the two months of pregnancy (stage of development). By three months, it goes down to $23.1 \pm 1.2 \mathrm{~mm}$ and afterward, slightly decreasing, stays static. The growth of antral follicles (more than $1 \mathrm{~cm}$ ) occurs in the ovaries; they can be palpated through the rectum and visualized using ultrasound examination. Follicles undergo atresia by obliteration type; white atretic bodies are formed.

In the absence of fertilization, marked cyclic changes progress in the ovarian glands. By the twelfth day after ovulation, the CL reaches its acme (Jaśkowski, 2019; Neves and Maques, 2002; Safonov, 2020; Vargas et al., 2015). It is believed that the mass of the CL after ovulation increases due to luteocytes hypertrophy and not to their hyperplasia, i.e., an increase in their number (Parkinson et al., 1994).

At the same time, (Neves and Maques, 2002) believe that the final development of the CL ended on the sixth 
day after ovulation, CL reaches the maximum value on the eighth day and persists until the eighteenth day. At the very end of the ovary cycle, on the 20th-21st day, the size of the CL decreased, it acquired dense consistency and a greyish-yellow tint of the incision due to fibrous changes. The CL undergoes regression in its entirety 2830 days after the beginning of the ovary cycle. At the same time, it acquired a fibrous structure and a light color (white body). It is believed that the CL persist for several ovary cycles and are visible in the incision in the form of reddish or light yellow formations.

Macroscopically, we distinguish three stages of the formation of the CL of the ovary cycle: The stage of formation (the first ten days after ovulation); the stage of acme (10-12 days of the ovary cycle); the stage of involution. We describe the morphological features of these stages to the accuracy of two to three days, which can serve as the criteria for post-slaughter determination of the stage of the ovary cycle, as well as for rectal ultrasound investigation of the ovarian glands.

In cows, the $\mathrm{CL}$ is represented by granulose-luteal cells of large size and by small theka-luteal cells. Thekaluteal cells are located mainly peripherally; they penetrate the thickness of the CL together with connective tissue trabeculae (Cools et al., 2013b; Walusimbi and Pate, 2014; Xavier et al., 2012). In cows, luteal cells of "average size" are described; they are allocated to a special class with significant morphofunctional features. Large luteal cells of luteinized follicular cysts and CL of the ovary cycle have significant differences according to cytometry data (Vargas et al., 2015), which may be of diagnostic significance when performing biopsy.

We have described in detail the histological, histochemical and enzymological features of cells and tissues forming the CL of pregnancy, ovary cycle, pathological forms of CL and atretic bodies. According to our data, the structural markers of various forms of luteal tissue are the size of luteal cells, the ratio of large, medium and small luteocytes, the ratio of phospholipids and neutral fats, the histological activity of oxidationreduction and hydrolytic enzymes in luteocytes, the structure of stromal-vascular components of the mesenchyma of luteal formations. According to our data based on histoenzymology, the corpora lutea at the beginning of pregnancy are the most active; the cyclic CL come after. The significant difference between them, when quantified, was found by $\mathrm{SDH}, \mathrm{NADH}_{2} \mathrm{DH}$ and $\mathrm{NADPH}_{2} \mathrm{DH}$. Persistent CL with active luteal and welldefined small theca-luteal cells is more active than CL with atrophied luteal cells and fibrously altered connective tissue. Luteal tissue in the ovaries at their hypofunction is close to the activity of enzymes in the persistent hypofunctional CL.

Various prostaglandins are involved in the regulation of luteal function, particularly during the formation and regression of the corpus luteum, as well as during pregnancy in cows. According to (Jonczyk et al., 2019), genes that trigger apoptosis are activated after the administration of prostaglandin $\mathrm{F} 2 \alpha$.

The use of in vivo production of $\mathrm{CL}$ tissue for morphological research, using the method developed by us for biopsy of CL of cows ' ovaries, made it possible to identify complex changes in ovarian glands in dynamics objectively. A similar approach was used in the works of (Kot et al., 1999) Our experimental study of luteolytic processes in CL under the action of a synthetic analog of prostaglandin F2 $\alpha$ showed that Klatiram had a pronounced luteolytic effect on the CL of cows. We have established the optimal dose of the drug for intramuscular administration $(500 \mathrm{mcg})$, which leads to optimal morphological changes in the parenchyma and CL stroma resembling spontaneous luteolytic processes in cows during the normal ovary cycle. Nevertheless, when using this drug, dystrophic changes are more pronounced not only in large luteocytes but also in small theka-luteal cells; against this background, macrophages of the CL stroma become more active and destroy the components of atrophied cells and apoptotic bodies. Besides, there is pronounced ischemia of the CL parenchyma. Therefore, the collagenisation of connective tissue is mild. So, rapid resorption of CL is not accompanied by a delay in involution. There are rapid growth and ovulation of the antral follicles. That is the purpose of using such drugs, for example, when synchronizing oestrus in cows.

\section{Conclusion}

Morphological criteria for determination of the stage of the ovarian cycle after slaughter or during rectal ultrasound examination of the ovarian glands are proposed.

We differentiated two types of persistent CL against the background of uterine pathology leading to anestrus: Actively secreting progesterone and hypofunctional ones. The latter also inhibits the growth of ovarian follicles and their ovulation. In the case of ovarian hypofunction, a significant number of atretic luteinized structures that reduced the endocrine and generative activity of the ovarian glands was found.

The leading role of microcirculatory disorders in $\mathrm{CL}$ degeneration has been proved, as well as the leading role of macrophages in luteolytic processes, in normal and pathological conditions and also in experimental administration of prostaglandin analog F2 $\alpha$ (Klatiram).

It is reasonable to conduct CL biopsy not only when diagnosing the condition of the ovarian glands but also when experimentally studying the effect of luteolytic and other drugs on the structures of the ovarian glands. Our method of CL biopsy makes it possible to quickly obtain a piece of the corpus luteum or other ovarian tissue 
sufficient for morphological and biochemical research without complex surgical interventions. The method is safe as regards the reproductive function of the animal; it does not require significant material costs. Besides, this puncture can be used for intraovarian injections, as well as for the treatment of cysts.

\section{Funding Information}

The authors received no financial support for the research, authorship and/or publication of this article.

\section{Author's Contributions}

All authors discussed the results and contributed to the final manuscript.

\section{Conflict of Interest}

The authors declared no potential conflicts of interest with respect to the research, authorship and/or publication of this article.

\section{Ethics}

This article does not contain any studies with animals performed by any of the authors.

\section{References}

Berisha, B., Schams, D., Rodler, D., Sinowatz, F., \& Pfaffl, M. W. (2018). Changes in the expression of prostaglandin family members in bovine corpus luteum during the estrous cycle and pregnancy. Molecular reproduction and development, 85(7), 622-634.

Cools, S., Van Den Broeck, W., De Vliegher, S., Piepers, S., Hostens, M., \& Opsomer, G. (2013a). Topographic distribution of the different cell types, connective tissue and vascular tissue/lumina within a functional bovine corpus luteum and its association with breed, type of fixation protocol and stage during the cycle. Reproduction in Domestic Animals, 48(4), 627-635.

Cools, S., Van Den Broeck, W., De Vliegher, S., Piepers, S., \& Opsomer, G. (2013b). The bovine luteal histological composition: a topographic point of view. Reproduction in Domestic Animals, 48(2), e29-e32.

Costa, N. P., Gonella-Diaza, A., Pugliesi, G., Maldonado, M. B. C., Scollari, S. C., Mello, B. P., ... \& Membrive, C. M. B. (2020). Effects of recombinant bovine somatotropin on pregnancy per artificial insemination, corpus luteum cellular composition and endometrial gland morphometry in beef cattle. Theriogenology, 141, 180-185.
Fields, M. J., \& Fields, P. A. (1996). Morphological characteristics of the bovine corpus luteum during the estrous cycle and pregnancy. Theriogenology, 45(7), 1295-1325.

Fields, M. J., Barros, C. M., Watkins, W. B., \& Fields, P. A. (1992). Characterization of large luteal cells and their secretory granules during the estrous cycle of the cow. Biology of reproduction, 46(4), 535-545.

Jameson, J. L., \& De Groot, L. J. (2015). Endocrinology: Adult and Pediatric E-Book.

Jaśkowski, B. M. (2019). Corpus luteum with a cavity in cattle: An overview of past and present knowledge. Medycyna Weterynaryjna, 75(6), 340-346.

Jonczyk, A. W., Piotrowska-Tomala, K. K., \& Skarzynski, D. J. (2019). Effects of prostaglandin F $2 \alpha$ (PGF $2 \alpha$ ) on cell-death pathways in the bovine Corpus Luteum (CL). BMC veterinary research, 15(1), 1-16.

Kot, K., Anderson, L. E., Tsai, S. J., Wiltbank, M. C., \& Ginther, O. J. (1999). Transvaginal, ultrasoundguided biopsy of the corpus luteum in cattle. Theriogenology, 52(6), 987-993.

Mogheiseh, A., Ahmadi, M. R., Nazifi, S., Mirzaei, A., \& Fallah, E. (2020). Destination of corpus luteum in postpartum clinical endometritis cows and factors affecting self-recovery. Veterinary and Animal Science, 9, 100067.

Neves, M. M., \& Marques Jr, A. P. (2002). Tamanho da amostra para estudo da proporção volumétrica dos constituintes do corpo lúteo bovino. Archives of Veterinary Science, 7(2).

Noakes, D. E., Parkinson, T. J., \& England, G. C. (2018). Arthur's Veterinary Reproduction and Obstetrics-E-Book. Elsevier Health Sciences.

Parkinson, T. J., Turvey, A., \& Jenner, L. J. (1994). A morphometric analysis of the corpus luteum of the cow during the estrous cycle and early pregnancy. Theriogenology, 41(5), 1115-1126.

Rivera, C. (2016). Progesterone: Functions, Uses and Research Insights. Nova Science Publishers, New York.

Safonov, V. (2020). Assessment of Heavy Metals in Milk Produced by Black-and-White Holstein Cows from Moscow. Current Research in Nutrition and Food Science Journal, 8(2), 410-415.

Sawyer, H. R. (1995). Structural and functional properties of the corpus luteum of pregnancy. Journal of Reproductionand Fertility Supplement49, 97, 110.

Siqueira, L. G., Arashiro, E. K., Ghetti, A. M., Souza, E. D., Feres, L. F., Pfeifer, L. F., ... \& Viana, J. H. (2019). Vascular and morphological features of the corpus luteum 12 to 20 days after timed artificial insemination in dairy cattle. Journal of dairy science, 102(6), 5612-5622. 
Skovorodin, E. N., Gimranov, V. V., Karimov, F. A., Kirilov, V. G., Bazekin, G. V., Gatiyatullin, I. R., ... \& Khokhlov, R. Y. (2018). Morphogenesis of bovine ovaries in prenatal ontogenesis in norm and in pathology of metabolism in cows-mothers. Journal of Engineering and Applied Sciences, 13(S11), 8768-8781.

Vargas, L. R., Xavier, P. R., Rezende, C. A., Neves, M. M., \& Marques Júnior, A. P. (2015). Morfologia e grânulos citoplasmáticos do corpo lúteo de vacas aneloradas (Bos taurus indicus) gestantes e não gestantes. Arquivo Brasileiro de Medicina Veterinária e Zootecnia, 67(2), 411-416.
Walusimbi, S. S., \& Pate, J. L. (2014). Luteal cells from functional and regressing bovine corpora lutea differentially alter the function of gamma delta $\mathrm{T}$ cells. Biology of reproduction, 90(6), 140-1.

Xavier, P. R., Leão, R. A. C., Oliveira e Silva, P. V. D., \& Marques Júnior, A. P. (2012). Histological characteristics of the corpus luteum of Nelore cows in the first, second and third trimester of pregnancy. Arquivo Brasileiro de Medicina Veterinária e Zootecnia, 64(2), 505-509. 